\title{
Battery Life of Portable Home Ventilators: Effects of Ventilator Settings
}

\author{
Line Falaize, Karl Leroux, Hélène Prigent MD PhD, Bruno Louis PhD, Sonia Khirani PhD, \\ David Orlikowski MD PhD, Brigitte Fauroux MD PhD, and Frédéric Lofaso MD PhD
}

\begin{abstract}
BACKGROUND: The battery life (BL) of portable home ventilator batteries is reported by manufacturers. The aim of this study was to evaluate the effects of ventilator mode, breathing frequency, PEEP, and leaks on the BL of 5 commercially available portable ventilators. METHODS: The effects of the ventilator mode (volume controlled-continuous mandatory ventilation [VC-CMV] vs pressure support ventilation [PSV]), PEEP $5 \mathrm{~cm} \mathrm{H} \mathrm{H}_{2} \mathrm{O}$, breathing frequency $(10,15$, and 20 breaths/ min), and leaks during both volume-targeted ventilation and PSV on the BL of 5 ventilators (Elisée 150, Monnal T50, PB560, Vivo 50, and Trilogy 100) were evaluated. Each ventilator was ventilated with a test lung at a tidal volume of $700 \mathrm{ml}$ and an inspiratory time of $1.2 \mathrm{~s}$ in the absence of leaks. RESULTS: Switching from PSV to VC-CMV or the addition of PEEP did not significantly change ventilator $B L$. The increase in breathing frequency from 10 to 20 breaths/min decreased the BL by $18 \pm 11 \%(P=.005)$. Leaks were associated with an increase in BL during the VC-CMV mode $(18 \pm 20 \%, P=.04)$ but a decrease in BL during the PSV mode $(-13 \pm 15 \%, P=.04)$. CONCLUSIONS: The BL of home ventilators depends on the ventilator settings. $\mathrm{BL}$ is not affected by the ventilator mode (VC-CMV or PSV) or the addition of PEEP. BL decreases with an increase in breathing frequency and during leaks with a PSV mode, whereas leaks increase the duration of ventilator BL during VC-CMV. Key words: home ventilators; portable ventilators; pressure support; leaks; volume-targeted mode; batteries. [Respir Care 2014;59(7):1048-1052. (C) 2014 Daedalus Enterprises]
\end{abstract}

\section{Introduction}

Improved ICU care has resulted in many patients surviving acute respiratory failure and requiring prolonged

\footnotetext{
Ms Falaize and Drs Prigent, Orlikowski, and Lofaso are affiliated with Service de Physiologie-Explorations Fonctionnelles, Services de Réanimation Médicale, et Centre d'Innovations Technologiques, Unité Mixte de Recherche 805, Hôpital Raymond Poincaré, Assistance Publique Hôpitaux de Paris, Garches, France, and EA 4497, Université de Versailles Saint-Quentin-en-Yvelines, France. Mr Leroux is affiliated with ASV Santé, Gennevilliers, France. Dr Louis is affiliated with Institut National de la Santé et de la Recherche Médicale, U995, Créteil, France; Faculté de Médecine, Université Paris Est, Créteil, France; and Centre National de la Recherche Scientifique, ERL 7240, Créteil, France. Drs Khirani and Fauroux are affiliated with Pediatric Pulmonary Department, Hôpital Armand Trousseau, Assistance Publique Hôpitaux de Paris, Institut National de la Santé et de la Recherche Médicale, U955, Créteil, France, and Pierre et Marie Curie University, Paris, France. Dr Khirani is also affiliated with S2A Santé, Ivry-sur-Seine, France.
}

The authors have disclosed no conflicts of interest. mechanical ventilation during convalescence that should be addressed outside the ICU because of reduced costs, enhanced quality of life, and reduction in hospital-borne infections. ${ }^{1}$ The transition from an ICU ventilator to a home ventilator is then necessary. Home ventilators are also useful for patients developing chronic respiratory failure due to neuromuscular and chest wall disorders. ${ }^{2}$ These home ventilators can be battery-powered for safety when alternating current power is unavailable. Batteries allow ventilator portability and therefore patients' mobility when patients are totally ventilator-dependent. To be considered as life-support equipment, ventilators should have reliable

\footnotetext{
Correspondence: Frédéric Lofaso MD PhD, Service de Physiologie-Explorations Fonctionnelles, Hôpital Raymond Poincaré, 104 Boulevard Raymond Poincaré, 92380 Garches, France. E-mail: f.lofaso@rpc. ap-hop-paris.fr.
}

DOI: $10.4187 /$ respcare.02711 
batteries, ${ }^{3}$ and most of the life-support home ventilator manufacturers claim a battery duration of $>8 \mathrm{~h}$ considering internal and external batteries. In fact, ventilator battery life (BL) is expected to depend not only on the characteristics of the batteries and the ventilator technology but also on the ventilator settings and the presence of leaks, which are common during both noninvasive and invasive ventilation through a tracheotomy when using an uncuffed tube. ${ }^{4-6}$

The aim of this study was to evaluate the effects of ventilator mode (volume controlled-continuous mandatory ventilation [VC-CMV] vs pressure support ventilation [PSV]), breathing frequency, PEEP, and leaks on the BL of 5 commercially available portable ventilators.

\section{Methods}

\section{Experimental Bench}

Each ventilator was connected via its standard circuit to a chamber Michigan test lung (MII VentAid TTL, Michigan Instruments, Grand Rapids, Michigan). To simulate the mechanical characteristics of the respiratory system of a healthy adult, the compliance of the testing chamber was adjusted to $100 \mathrm{~mL} / \mathrm{cm} \mathrm{H}_{2} \mathrm{O}$, and a parabolic resistance ( $2.7 \mathrm{~cm} \mathrm{H} \mathrm{H}_{2} \mathrm{O} / \mathrm{L} / \mathrm{s}$ at $1 \mathrm{~L} / \mathrm{s}$ and $10.8 \mathrm{~cm} \mathrm{H}_{2} \mathrm{O} / \mathrm{L} / \mathrm{s}$ at $2 \mathrm{~L} / \mathrm{s}$; Rp5 parabolic resistance, Michigan Instruments) was added between the chamber and the ventilator.

Airway pressure and flow were recorded at the end of the ventilator circuit using a pressure transducer (Validyne DP $45 \pm 56 \mathrm{~cm} \mathrm{H}_{2} \mathrm{O}$, Northridge, California) and a pneumotachograph (Fleisch No. 2, Phipps \& Bird, Richmond, Virginia) with a pressure differential transducer (Validyne DP $45 \pm 3.5 \mathrm{~cm} \mathrm{H}_{2} \mathrm{O}$ ), respectively. Ventilator performance during the trials was determined by recording pressure and flow signal outputs continuously digitized at $10 \mathrm{~Hz}$ (MP100, Biopac Systems, Goleta, California) and stored in a microcomputer for further analysis.

\section{Procedure}

Five ventilators available in France for home ventilation were tested (Table 1). Each ventilator tested was up to date with respect to preventive maintenance schedule and passed all required pre-use calibration/verification procedures recommended by each manufacturer. The internal batteries were exchanged for new ones, and an optional external or detachable battery was added when available. Each ventilator battery was charged prior to testing in accordance with the manufacturer's recommendation. Each ventilator was set to deliver a tidal volume $\left(\mathrm{V}_{\mathrm{T}}\right)$ of $700 \mathrm{~mL}$ and an inspiratory time of $1.2 \mathrm{~s}$ in the absence of leaks.

Each ventilator was operated on alternating current power for $5 \mathrm{~min}$, during which all ventilator settings were set and

\section{QUICK LOOK}

\section{Current knowledge}

Battery life (BL) of portable ventilators is impacted by size and type of battery, as well as by ventilator settings. Increasing PEEP and minute ventilation and the use of pressure control is associated with greater power consumption. Patient characteristics also impact BL; increased load (higher resistance and lower compliance) increases power consumption.

\section{What this paper contributes to our knowledge}

In a model of normal lung mechanics, the BL of portable ventilators was similar using both volume control and pressure support. A PEEP up to $5 \mathrm{~cm} \mathrm{H}_{2} \mathrm{O}$ did not shorten BL. Battery life was shortened by an increase in minute ventilation and in the presence of leaks during pressure support.

confirmed. Each test run was initiated by disconnecting the alternating current power cord from the ventilator. Each test was considered complete when inspiratory flow output ceased totally.

The baseline ventilator mode was VC-CMV with a breathing frequency of 15 breaths/min. This baseline condition was tested in duplicate for each ventilator model in order to check that the difference in BL was $<2 \%$ of the mean duration, which was taken into account for the analysis. Thereafter, we evaluated the effects of (1) breathing frequency by testing 10 and 20 breaths/min, (2) PEEP $5 \mathrm{~cm} \mathrm{H}_{2} \mathrm{O}$, (3) ventilator mode by evaluating PSV while maintaining $\mathrm{V}_{\mathrm{T}}$ and baseline breathing frequency, and (4) leaks during both VC-CMV and PSV using a calibrated leak valve $(2.2 \mathrm{~mm}$ in diameter; respiratory muscle training valve, Ambu, Glen Burnie, Maryland) added to the circuit between the ventilator and the pneumotachograph. We also evaluated the ability of each portable ventilator to deliver the set $\mathrm{V}_{\mathrm{T}}$ as battery power diminished.

\section{Statistical Analysis}

Statistical analysis included a Friedman test for the effects of breathing frequency and a Wilcoxon analysis for the effects of PEEP, ventilator mode (VC-CMV vs PSV), and leaks under both VC-CMV and PSV conditions. Differences were considered statistically significant when $P$ was $<.05$.

\section{Results}

The 5 tested ventilators are listed in Table 1, as well as battery configuration and duration under each condition. 
Table 1. Ventilators and Batteries Tested and Duration in Each Experimental Condition

\begin{tabular}{|c|c|c|c|c|c|}
\hline & \multicolumn{5}{|c|}{ Ventilator } \\
\hline & Elisée 150 & Monnal T50 & PB560 & Vivo 50 & Trilogy 100 \\
\hline Internal battery/external battery & Yes/Yes & Yes/Yes & Yes/Yes & Yes/Yes & Yes/Yes \\
\hline Ventilator + internal battery weight $(\mathrm{kg})$ & 4.0 & 5.3 & 4.5 & 5.2 & 5.0 \\
\hline External battery weight $(\mathrm{kg})$ & 0.8 & 2.4 & 1.7 & 1.5 & 0.5 \\
\hline Reported duration* & $12 \mathrm{~h}$ & $12 \mathrm{~h}$ & $9 \mathrm{~h}$ & $11 \mathrm{~h}, 30 \mathrm{~min}$ & $6 \mathrm{~h}$ \\
\hline \multicolumn{6}{|l|}{ VC-CMV f } \\
\hline 10 breaths/min & $14 \mathrm{~h}, 30 \mathrm{~min}$ & $15 \mathrm{~h}, 15 \mathrm{~min}$ & $20 \mathrm{~h}, 14 \mathrm{~min}$ & $13 \mathrm{~h}, 5 \mathrm{~min}$ & $12 \mathrm{~h}, 5 \mathrm{~min}$ \\
\hline 15 breaths/min & $13 \mathrm{~h}$ & $13 \mathrm{~h}, 30 \mathrm{~min}$ & $17 \mathrm{~h}$ & $13 \mathrm{~h}, 5 \mathrm{~min}$ & $9 \mathrm{~h}, 21 \mathrm{~min}$ \\
\hline 20 breaths/min & $12 \mathrm{~h}, 35 \mathrm{~min}$ & $12 \mathrm{~h}, 30 \mathrm{~min}$ & $15 \mathrm{~h}, 35 \mathrm{~min}$ & $12 \mathrm{~h}, 36 \mathrm{~min}$ & $8 \mathrm{~h}, 15 \mathrm{~min}$ \\
\hline 15 breaths/min + leak & $14 \mathrm{~h}, 35 \mathrm{~min}$ & $14 \mathrm{~h}, 30 \mathrm{~min}$ & $19 \mathrm{~h}, 15 \mathrm{~min}$ & $13 \mathrm{~h}, 40 \mathrm{~min}$ & $12 \mathrm{~h}, 45 \mathrm{~min}$ \\
\hline 15 breaths/min + PEEP & $11 \mathrm{~h}, 50 \mathrm{~min}$ & $13 \mathrm{~h}, 40 \mathrm{~min}$ & $17 \mathrm{~h}, 25 \mathrm{~min}$ & $11 \mathrm{~h}, 5 \mathrm{~min}$ & $7 \mathrm{~h}, 50 \mathrm{~min}$ \\
\hline \multicolumn{6}{|l|}{ PSV f } \\
\hline 15 breaths/min & $14 \mathrm{~h}, 30 \mathrm{~min}$ & $13 \mathrm{~h}, 25 \mathrm{~min}$ & $18 \mathrm{~h}, 30 \mathrm{~min}$ & $11 \mathrm{~h}, 55 \mathrm{~min}$ & $12 \mathrm{~h}, 32 \mathrm{~min}$ \\
\hline 15 breaths/min + leak & $13 \mathrm{~h}, 40 \mathrm{~min}$ & $13 \mathrm{~h}, 20 \mathrm{~min}$ & $13 \mathrm{~h}, 30 \mathrm{~min}$ & $11 \mathrm{~h}, 45 \mathrm{~min}$ & $8 \mathrm{~h}, 40 \mathrm{~min}$ \\
\hline \multicolumn{6}{|c|}{$\begin{array}{l}\text { For each model, the same ventilator and the same batteries were tested twice. } \\
\text { * Values in a condition reported by all of the manufacturers (except for Trilogy 100, for which the manufacturer did not explain the condition): breathing frequency }(\mathrm{f})=15 \text { breaths/min, targeted } \\
\text { inspiratory pressure }=20 \mathrm{~cm} \mathrm{H}_{2} \mathrm{O} \text {, no PEEP (except for Vivo } 50 \text {, PEEP } 8 \mathrm{~cm} \mathrm{H}_{2} \mathrm{O} \text { ). } \\
\text { VC-CMV = volume controlled-continuous mandatory ventilation } \\
\text { PSV = pressure support ventilation }\end{array}$} \\
\hline
\end{tabular}

To obtain an inspiratory time of $1.2 \mathrm{~s}$ in the absence of leaks, the PSV flow cycle setting was adjusted to 24, 20, 20, 24, and 22\% of peak inspiratory flow for the Elisée 150 (ResMed, San Diego, California), Monnal T50 (Air Liquide Medical Systems, Antony, France), PB560 (Covidien, Mansfield, Massachusetts), Trilogy 100 (Philips Respironics, Murrysville, Pennsylvania), and Vivo 50 (Breas Medical, St Priest, France), respectively.

An increase in breathing frequency decreased ventilator BL $(P=.005)$, whereas the addition of PEEP did not $(P=$ .22). Switching from PSV to VC-CMV did not change ventilator $\mathrm{BL}(P=.22)$. Leaks were associated with an increase in ventilator BL during VC-CMV $(P=.043)$ and a decrease during PSV $(P=.043)$. All ventilators were able to maintain a constant $\mathrm{V}_{\mathrm{T}}$ until the battery failed.

\section{Discussion}

The main results of our study are that the BL of home ventilators decreases with an increase in breathing frequency, whereas switching from PSV to VC-CMV and the addition of PEEP $5 \mathrm{~cm} \mathrm{H}_{2} \mathrm{O}$ do not affect ventilator BL. Leaks are associated with an increase in ventilator $\mathrm{BL}$ during VC-CMV and a decrease during PSV.

\section{Effect of Breathing Frequency}

The increase in breathing frequency from 10 to 20 breaths/min $(+100 \%)$ was associated with a decrease in ventilator $\mathrm{BL}$ of $18 \pm 11 \%$. Therefore, the decrease in ventilator $\mathrm{BL}$ is not inversely proportional to the increase in breathing frequency. The ventilators tested in this study use turbines that are also powered during expiration although at a lower speed. Accordingly, the battery drain is more important during inspiration but not limited to it, meaning that ventilator BL is not solely dependent on the number of inspiratory cycles.

\section{Effects of PEEP and Mode of Mechanical Ventilation}

Surprisingly, PEEP did not affect ventilator BL. This may be explained by the low level of PEEP tested in our study considering that, $12 \mathrm{y}$ ago, a study demonstrated that PEEP $20 \mathrm{~cm} \mathrm{H}_{2} \mathrm{O}$ had important effects on BL in electrically driven portable ventilators. ${ }^{7}$ Nevertheless, the use of PEEP at $20 \mathrm{~cm} \mathrm{H}_{2} \mathrm{O}$ is now less common than at $5 \mathrm{~cm} \mathrm{H}_{2} \mathrm{O}$. It is also probable that the new generation of home ventilators requires less power for operating the solenoid dedicated to driving the exhalation valve compared with the older ones. In addition, when analyzing the individual data, we observed that 2 of the 5 ventilators had a longer BL with the addition of PEEP. We checked these results by duplicating the PEEP condition with these 2 ventilators and observed similar results. One possible explanation could be a lower decrease in turbine speed during expiration in order to meet the PEEP level, which may reduce the energy cost of turbine acceleration during inspiration.

\section{VC-CMV Versus PSV}

Changing the VC-CMV mode for a PSV mode did not affect ventilator BL. This contrasts with the data reported 
by Campbell et al, ${ }^{7}$ who observed a decrease in ventilator BL with PSV because of the need for a higher flow delivery during early inspiration with this mode. In fact, 3 ventilators had a constant flow during VC-CMV (Elisée 150, PB560, and Trilogy 100), whereas the other two (Vivo 50 and Monnal T50) presented pressure and flow wave contours during VC-CMV that were very similar to those during PSV. When comparing differences in $\mathrm{BL}$ and in pressure and flow wave contours during $\mathrm{VC}-\mathrm{CMV}$ and PSV for each ventilator, there seemed to be no effect between various pressure and flow wave contours on ventilator BL when the same volume was delivered during a similar inspiratory time.

\section{Effects of Leaks During VC-CMV and PSV}

The increase in ventilator BL during leaks with VC-CMV may be explained by the decrease in impedance imposed on the ventilator when the circuit is partially opened to the atmosphere. On the other hand, the decrease in ventilator BL during leaks with PSV may be explained by the increase in turbine speed to reach the target pressure despite the opening of the circuit. In addition, leaks induce an increase in the inspiratory time because, during PSV, the flow cycle occurs when the inspiratory flow falls below a set percentage of peak inspiratory flow. It has been demonstrated that flow cycle criteria are less easily attained during leaks. Indeed, leaks may prolong inspiratory time. ${ }^{5}$

\section{Limitations and Clinical Implications}

Because a short BL could increase the risk of power failure and because we have recently lost a home-ventilated patient for this unique reason, we believe that our bench evaluation is clinically relevant. Our experimental condition was ideal considering that it represents a subject with a normal respiratory system impedance. Unfortunately, we did not test the effects of decreasing compliance and increasing resistance of the simulated respiratory system. However, because leak occurrence (which reduces the impedance imposed on the ventilator) increased $\mathrm{BL}$ during $\mathrm{VC}-\mathrm{CMV}$, we can speculate that, when impedance increases, BL decreases when delivering the same $\mathrm{V}_{T}$ at the same frequency. Similarly, because the increase in respiratory system impedance during PSV should reduce the delivered $\mathrm{V}_{\mathrm{T}}$, it would be necessary to increase the level of PSV to obtain the desired $\mathrm{V}_{\mathrm{T}}$, which reduces BL.

It is difficult to state that the manufacturers underestimate BL (Table 1) considering that this duration can depend on the patient's characteristics (mechanical properties of the respiratory system, patient's respiratory muscle activity, and patient's minute ventilation need) and on the ventilator settings, which were different considering that manufacturers prefer to use the pressure-targeted mode, whereas our baseline condition was VC-CMV. ${ }^{8}$ Nevertheless, even if we can understand the difference between our results and the information on BL delivered by the manufacturers, the BL delivered by the manufacturers is not representative of the differences that we observed between ventilators considering that, for example, the ventilator that had the highest BL in our bench study, for each condition, was the penultimate one when comparing the company's reported duration (Table 1). This suggests that all manufacturers should delineate the conditions of mechanical ventilation used when measuring BL.

Finally, our study cannot give to prescribers an idea of BL considering that this can change with the patient's characteristics, but it does provide information that could be used at the bedside. Our results suggest that for the same $\mathrm{V}_{\mathrm{T}}$ adjustment and in the absence of leaks, there is no difference in BL between VC-CMV and PSV. However, in the presence of leaks, BL increases systematically during VC-CMV and decreases during PSV. This result reinforces the preference of VC-CMV over PSV when using mouthpiece ventilation during the daytime. ${ }^{9}$ Our results also suggest that for all ventilators, the BL (for all models) varies significantly from that reported by the manufacturers. Therefore, clinicians should not rely on the BL delivered by the manufacturer. Moreover, if a low level of PEEP is required, preference should be given to the ventilators that improve BL. Interestingly, if PEEP is used to improve the speech of patients with tracheotomies, the activation of a key-pinch switch under the patient's control may be an option for the future ${ }^{10}$ so that PEEP is used only when needed (ie, for speech).

\section{Conclusion}

The BL of home ventilators depends on the ventilator settings. When testing a healthy subject profile on a lung model, BL is not affected by the ventilator mode (VCCMV vs PSV) or the addition of a moderate level of PEEP. BL decreases with an increase in breathing frequency and in the presence of leaks during PSV, whereas leaks increase the duration of ventilator BL during VCCMV. Clinicians should not base their instructions regarding BL on the manufacturer's data. Finally, clinicians' and families' knowledge of ventilator BL and the effects of various ventilator settings could reduce the risk of equipment failure and potential adverse clinical outcomes.

\section{REFERENCES}

1. King AC. Long-term home mechanical ventilation in the United States. Respir Care 2012;57(6):921-930; discussion 930-922.

2. Ambrosino N, Carpenè N, Gherardi M. Chronic respiratory care for neuromuscular diseases in adults. Eur Respir J 2009;34(2):444-451.

3. Blakeman TC, Robinson BR, Branson RD. Battery performance of 4 intensive care ventilator models. Respir Care 2010;55(3):317-321. 


\section{Ventilator BATTERy LIFE}

4. Gonzalez J, Sharshar T, Hart N, Chadda K, Raphä̈l JC, Lofaso F. Air leaks during mechanical ventilation as a cause of persistent hypercapnia in neuromuscular disorders. Intensive Care Med 2003; 29(4):596-602.

5. Prigent H, Samuel C, Louis B, Abinun MF, Zerah-Lancner F, Lejaille $\mathrm{M}$, et al. Comparative effects of two ventilatory modes on speech in tracheostomized patients with neuromuscular disease. Am J Respir Crit Care Med 2003;167(2):114-119.

6. Pearson FG, Goldberg M, da Silva AJ. A prospective study of tracheal injury complicating tracheostomy with a cuffed tube. Ann Otol Rhinol Laryngol 1968;77(5):867-882.

7. Campbell RS, Johannigman JA, Branson RD, Austin PN, Matacia G, Banks GR. Battery duration of portable ventilators: effects of control variable, positive end-expiratory pressure, and inspired oxygen concentration. Respir Care 2002;47(10):1173-1183.

8. Lofaso F, Prigent H, Tiffreau V, Menoury N, Toussaint M, Monnier $\mathrm{AF}$, et al. Long-term mechanical ventilation equipment for neuromuscular patients: meeting the expectations of patients and prescribers. Respir Care 2014;59(1):97-106.

9. Boitano LJ, Benditt JO. An evaluation of home volume ventilators that support open-circuit mouthpiece ventilation. Respir Care 2005; 50(11):1457-1461.

10. Garguilo M, Leroux K, Lejaille M, Pascal S, Orlikowski D, Lofaso F, Prigent H. Patient-controlled positive end-expiratory pressure with neuromuscular disease: effect on speech in patients with tracheostomy and mechanical ventilation support. Chest 2013;143(5):1243-1251.

This article is approved for Continuing Respiratory Care Education

credit. For information and to obtain your CRCE

(free to AARC members) visit 